\title{
INVOLVEMENT OF THE NERVOUS SYSTEM IN REITER'S SYNDROME
}

\author{
BY
}

\author{
GEORGE W. CSONKA
}

St. Mary's Hospital, London

Reiter's syndrome is a condition of unknown aetiology, generally thought to be of infective origin. It occurs mainly in young men and is characterized by urethritis, arthritis, and conjunctivitis. Less common findings include ankylosing spondylitis, iritis, balanitis, keratoderma blennorrhagica and other skin lesions, stomatitis, and inflammations of the tendons and fasciae. According to the literature neurological complications seem to be extremely rare, and for this reason the following case is presented.

\section{Case Report}

A labourer, aged 29 years, had suffered from recurrent attacks of urethritis, acute polyarthritis, and conjunctivitis since he was 17 years old. Between attacks he felt perfectly well and was able to do a full day's work. In May, 1950, he attended St. Mary's Hospital for the first time, with non-specific urethritis (N.S.U.): 8 days later, arthritis, circinate balanitis, and conjunctivitis developed, his fourth attack of Reiter's syndrome. He was admitted to hospital and the symptoms subsided gradually during the next 2 months, when he left hospital against advice. A few days later he developed acute urinary retention, double vision, nausea, dizziness, and an acute pain in the back of the neck. He also noticed a tickling sensation on the right side of his face and, some days later, a heaviness in both legs. Double vision and dizziness improved after 3 weeks and the difficulty of micturition after 6 weeks, and the rest of the neurological symptoms disappeared within the next 3 months.

He remained well until December, 1951, when he contracted gonorrhoea which was followed by persistent N.S.U. A week later arthritis and conjunctivitis appeared, together with double vision, dizziness, and vomiting. The locomotor and neurological symptoms again subsided gradually and the patient felt fit 5 months later when his convalescence was temporarily interrupted by thrombophlebitis of the left calf veins. In August, 1953, a further attack of urethritis followed a venereal risk and this was, in turn, followed within a week by arthritis, conjunctivitis, pain over the sacroiliac joints, thrombophlebitis of the calf veins on the right side, and keratoderma blennorrhagica. This attack was not accompanied by a recurrence of neurological symptoms and he made a good recovery within 3 months.

He remained well until March, 1955, when dizziness, $\dot{\omega}$ diplopia, and heaviness of the legs recurred. This was $\dot{\omega}$ followed, 2 weeks later, by slight N.S.U., arthritis, and $\omega_{\mathcal{H}}$ conjunctivitis, and at the same time a rash with the characteristics of erythema multiforme of the iris type appeared on the forearms and legs. According to the $\vec{c}$ patient, the most unusual feature of this latest episode was the fact that there had been no sexual intercourse for at least 3 months preceding its onset, unlike the earlier attacks. Symptomatic recovery was rapid both as regards locomotor and neurological symptoms, and he was discharged from hospital in May, 1955. He has n@ attended since that time.

The main clinical events are shown chronological in the Figure (opposite).

Personal History.-No major or relevant illness.

Family History.-Negative for rheumatic and neurological disorders.

Examination.-In the course of the seven attacks of Reiter's syndrome, most of the joints of the lower limbs were involved, but only the left wrist and right shoulder of the upper limbs. Of the central joints, the sacro-iliac articulations were markedly tender and painful in the later attacks; the rest of the spine was symptom free. Between attacks, the previously-affected peripheral joints were clinically and functionally normal. Plantar fasciitis with painful heels was present with every attack. Bilateral angular conjunctivitis was seen early with every episode of arthritis and lasted from 3 days to 2 weeks. Circinate balanitis developed for the first time during the fourth attack.

Nervous System (January 2, 1952).-The optic disks were normal; the visual acuity was $6 / 6$ in the right eye $N$ and $6 / 12$ in the left; the fields of vision were full. There was slight ptosis on the left side, and a sustained fine $N$ rapid nystagmus with a rotary element developed in both $\mathrm{\omega}$ eyes on lateral conjugate deviation and was more marked on looking to the left.

There was a VIth nerve palsy on the left side and $\varrho$ hyperalgesia over the right side of the face, including all $\overline{\mathscr{D}}$ three divisions of the fifth cranial nerve, and hyperaesthesia over the 2nd and 3rd divisions. Corneal 
Age (yrs)

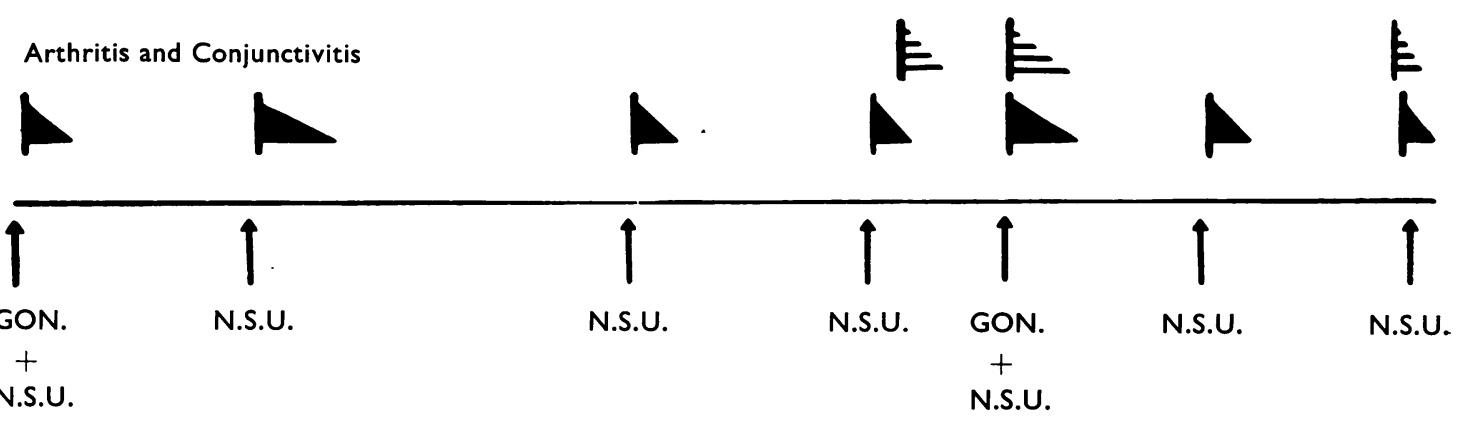

Episodes of Urethral Infection

Figure.-Diagram showing clinical symptoms during successive episodes of urethral infection.

reflexes and motor function of the nerve were normal. There were no other sensory changes. There was right lower facial weakness; the other cranial nerves were normal.

The left arm fell away and was more easily displaced than its fellow and there was clumsiness in the performance of rapid alternating movements of the left forearm. The motor functions were otherwise normal.

The arm reflexes were normal; knee jerks pathologically brisk on both sides; ankle jerks normal; plantar responses flexor; abdominal reflexes absent.

In the next few days there was some extension of the hyperalgesia into the territory of the right cervical plexus and marked increase of the ptosis on the left side.

(August 7, 1953) The neurological symptoms and signs were less marked, except for the left external rectus paralysis which remained unchanged. The reflexes of the lower limbs were now sluggish.

(March 7, 1955) The only abnormal neurological sign was the left external rectus paralysis.

The patient was mentally normal throughout his illness.

Laboratory Investigations.-Haemoglobin $13 \cdot 3$ to $14.8 \mathrm{~g}$. per $100 \mathrm{ml}$. (several estimations); mean corpuscular diameter $7 \cdot 2 \mu$; total white count showed a variable slight neutrophil leucocytosis during the acute phases of arthritis.

The Wassermann, Kahn, and gonococcal complementfixation tests were performed during every attack with negative results.

The erythrocyte sedimentation rate (Westergren) was raised with every arthritic episode, the highest reading being $106 \mathrm{~mm}$./hr.

The cerebrospinal fluid (January 25, 1952) was clear and colourless with normal dynamics; no cells were seen; protein $15 \mathrm{mg}$. per $100 \mathrm{ml}$.; Pandy negative; Lange 000000000 ; Wassermann negative. A further sample collected on March 10, 1952 gave identical results.
Total serum protein (January 3,1952 ) was $7 \cdot 4$ g. per $100 \mathrm{ml}$; ; albumin $4 \cdot 7 \mathrm{~g}$. per $100 \mathrm{ml}$.; globulin $2 \cdot 7 \mathrm{~g}$. per $100 \mathrm{ml}$. Similar results were obtained during the attacks in 1953 and 1955.

The Rose-Waaler differential agglutination test (D.A.T.) was negative on January 9, 1952, and August 27, 1953. C-reactive protein was negative.

Catheter specimen urine showed pus cells repeatedly and occasional red blood cells. Cultures yielded $E$. coli and enterococci.

The urethral discharge was sterile, except on the two occasions in 1943 and 1951, when gonococci were present. Prostatic fluid obtained by massage in April, 1955, showed from twenty to thirty pus cells per high-power field.

Investigations for pleuro-pneumonia-like organisms (PPLO) were undertaken by Dr. Klieneberger-Nobel at the Lister Institute, London, on material from the urethra, conjunctivae, and synovial fluid from an affected knee joint, with negative results; the serum complementfixation test against PPLO was also negative (April 14, 1955).

Radiology.-X-rays of the chest, skull, hands, and cervical, dorsal, and lumbar spine were normal. The feet showed bilateral calcaneal spurs and some periosteal new bone formation at the base of the right medial malleolus. Two small calcified opacities were noted behind the lower end of the right tibia and were thought to be phleboliths. The sacro-iliac joints showed subarticular sclerosis (April 4, 1955).

Treatment and Progress.-The initial non-specific urethral infections were treated with a variety of antibiotics (aureomycin, terramycin, sulphadiazine, and streptomycin) with little improvement of the urethritis and without effect on the development of arthritis and other complications. Gonorrhoea was treated with procaine penicillin injections, which apparently cleared the gonococcus, but did not prevent the emergence of Reiter's syndrome. During the attacks of arthritis, the 
main lines of treatment were salicylates in full doses and artificial fever therapy induced by intravenous injection of typhoid vaccine (T.A.B.) with temporary improvement in the affected joints. ACTH $25 \mathrm{mg}$. daily, given by slow intravenous drip from April 16, 1952, resulted in an immediate response of the affected joints, but without influencing the neurological signs and symptoms. The neurological disorder appeared at its most severe and widespread a few days after its onset and became less marked on the occasion of the recurrences over the next 5 years. No new neurological features occurred in the later attacks.

\section{Discussion}

In view of the established relationship of Behcet's syndrome with neurological involvement (Knapp, 1941; Berlin, 1944; Phillips and Scott, 1955; Pallis and Fudge, 1956; Evans, Pallis, and Spillane, 1957), this diagnosis was carefully considered, especially as Behcet's syndrome bears a superficial likeness to Reiter's syndrome. However, circinate balanitis and keratoderma blennorrhagica, which were present in our case, are not found in Behcet's syndrome, nor is the relationship of the recurrent attacks with venereal urethritis. Arthritis is uncommon in Behcet's syndrome (Lancet, 1958) and does not form a dominant and integral part of the illness as in Reiter's syndrome and in our patient.

A diagnosis of multiple sclerosis precipitated by genital infection seems unlikely, in view of the abrupt onset of a number of neurological signs and symptoms, which reached their greatest extent and severity early in the attack and from then onwards began to improve; furthermore, no new neurological lesions made their appearance after the first episode.

The possibility of a chance association of Reiter's syndrome with a neurological disorder of unknown aetiology cannot be disproved in this case, but a more direct relationship is favoured by the appearance of neurological symptoms soon after the onset of an attack of the syndrome and the subsequent lighting up of the nervous disorder by two further attacks.
Anatomically, the neurological signs and symptome in this young man are thought to be due to widespread involvement of the brain stem, but perhaps significantly, they cannot easily be fitted into any category of known primary nervous disease.

\section{Summary}

A case of recurrent Reiter's syndrome with clinical involvement of the central nervous system is reported. The neurological signs and symptoms closely follow the activity of the syndrome and it is suggested that the association is not merely fortuitous.

I am grateful to Dr. G. L. M. McElligott, Dr. H. Edwards and Mr. A. J. King for their helpful criticism and advice. This work was carried out under the aegis of the Medical Research Council Working Party on Non-Specific Urethritis, with the aid of a grant from the U.S. Public Health Service.

\section{REFERENCES}

Berlin, C. (1944). Arch. Derm. Syph. (Chicago), 49, 227.

Evans, A. D., Pallis, C. A., and Spillane, J. D. (1957). Lancet, 2, 349. Knapp, P. (1941). Schweiz. med. Wschr., 71, 1288.

Lancet (1958). 1, 421.

Pallis, C. A., and Fudge, B. J. (1956). A.M.A. Arch. Neurol. Psychiat.,

Phillips, D. L., and Scott, J. S. (1955). Lancet, 1, 366.

Implication du système nerveux dans le syndrome Reiter

RÉSUMÉ

On rapporte un cas de syndrome de Reiter recurrent avec implication clinique du système nerveux central. Les signes et les symptômes neurologiques accompagnent l'activité du syndrome de très près et on suggère que cette association n'est pas entièrement fortuite.

Implicación del sistema nervioso en el síndrome de Reiter SUMARIO

Se relata un caso de síndrome de Reiter recurrente con implicación clínica del sistema nervioso central. Los signos y los síntomas neurológicos siguen de muy cerca la actividad del sindrome y se sugiere que esta asociación no es enteramente fortuita. 